\title{
Alkalinizing Agent Preparation
}

National Cancer Institute

\section{Source}

National Cancer Institute. Alkalinizing Agent Preparation. NCI Thesaurus. Code C29729.

Used topically or systemically for management of metabolic acidosis, improved muscle contraction, and hyper-acidic conditions, Alkalinizing Agent Preparations contain one or more substances with basic properties, such as sodium bicarbonate, sodium citrate, and phosphate salts (potassium phosphate, sodium acid phosphate, and tribasic sodium phosphate). Usually the alkalinizing agent(s) acts as a proton acceptor, neutralizing the acidity of a biologic environment (skin, gastric content, urine, etc.) and raising the $\mathrm{pH}$. $(\mathrm{NCl04})$ 